\title{
Samenhang gedrag van huisartsopleiders met de door aios beleefde effectiviteit van de huisartsenstage
}

\author{
G. Locher, A.H. Blankenstein
}

\section{Samenvatting}

Inleiding en vraagstelling: Past de rol, die bij de vernieuwing van het onderwijs in de huisartsopleiding toebedeeld is aan de huisartsopleiders in de huisartsenpraktijk, bij het door hen ontwikkelde gedragspatroon? In deze studie wordt onderzocht welke gedragspatronen opleiders ontwikkeld hebben en hoe deze samenhangen met specifieke door de artsen in opleiding tot specialist (aios) ervaren leereffecten.

Methode: Aan 166 aios, die in $2003 \mathrm{t} / \mathrm{m} 2005$ het eerste jaar afsloten aan de huisartsopleiding VUmc, werden 17 gedragingen voorgelegd, waarvan zij de frequentie van voorkomen konden scoren op een vijfpuntsschaal. Gedragspatronen werden vastgelegd met behulp van factoranalyse. Per factor werden factorscores berekend. Daarnaast werd de aios gevraagd op een vijfpuntsschaal drie effectiviteitscriteria te beoordelen: 1) bijdrage van de stage aan de vorming tot huisarts, 2) bewustwording van de lacunes en 3) bewustwording van de kwaliteiten.

De samenhang van de gedragspatronen met de drie effectiviteitscriteria werd vastgesteld door correlaties te berekenen tussen de factorscores en de schaalscores op de drie effectiviteitscriteria.

Resultaten: 117 aios vulden de vragenlijsten in (respons 70\%). De factoranalyse leverde vier clusters van gedragingen op, benoemd als: 1) het geven van feedback, 2) het affectief coachen, 3) het stimuleren van zelfstudie en 4) het stimuleren van samenwerking in de praktijk. De hoogste correlatie werd gevonden tussen de derde factor en de door de aios ervaren bijdrage van de stage aan de vorming tot huisarts $(r=0.44, p=0.000)$.

Discussie: De huisartsen in opleiding ervaren hun stages in de huisartspraktijk als het meest leerzaam als huisartsopleiders zich vooral bezighouden met het begeleiden van de leeractiviteiten. (Locher G, Blankenstein AH. Samenhang gedrag van huisartsopleiders met de door aios beleefde effectiviteit van de huisartsenstage. Tijdschrift voor Medisch Onderwijs 2008;27(2):70-79.)

\section{Inleiding en vraagstelling}

Het curriculum van de huisartsopleiding is in een periode van vernieuwing. In die vernieuwing wordt meer accent gelegd op het vergaren van competenties door de artsen in opleiding tot specialist (aios) dan op het overdragen van kennis en vaardigheden. Tegelijkertijd krijgt het leren van de aios in de praktijk een zwaarder accent. Het gevolg is dat de aandacht zich meer gaat richten op het versterken van de docentvaardigheden van de huisartsopleider (hao), zoals coachings-, beoordelings- en toetsingsvaardigheden. ${ }^{1}$

Dat de hao's meer aandacht krijgen blijkt ook uit de activiteiten van de landelijke werkgroep 'Kwaliteit huisartsopleiders' van de Stichting Verenigde Universitaire Huisartsopleidingen (SVUH). Deze werkgroep heeft een lijst samengesteld van normen, waaraan een huisarts als opleider moet voldoen. ${ }^{2}$ Deze kwaliteitsnor- 
men hebben betrekking op 1) het huisartsgeneeskundig handelen, het handelen als model of als voorbeeld, 2) het onderwijskundig/didactisch handelen, en op 3) de randvoorwaarden voor praktijkonderwijs.

De lijst is een verzameling van de items kennis, vaardigheden en attitude. Aan de basis van dit product staat onder andere het werk van Boendermaker, die een onderzoek heeft gedaan naar de belangrijkste kwaliteiten waaraan huisartsen als opleiders moeten voldoen. Hieruit kwam naar voren dat een opleider de basale onderwijsmethoden moet kennen en deze kennis moet kunnen toepassen, met het accent op de vaardigheid om feedback te geven, te observeren, te analyseren en de aios aan te zetten tot reflectie. De didactische houding van de opleider wordt gekenmerkt door het geven van ruimte aan de aios, respect voor en interesse in de aios en het bereikbaar zijn. Als persoonlijke eigenschappen worden genoemd: enthousiasme, flexibiliteit, geduld en zelfinzicht. Mede daarop baseerde Boendermaker een instrument waarmee hij kon toetsen in hoeverre de huisarts 'meesteropleider' is. ${ }^{3}$ Later gepubliceerd Amerikaans onderzoek geeft als resultaat dat opleiders enthousiast moeten zijn en klinisch competent.

De stagiaires in het ziekenhuis gaven aan respect voor hun autonomie en onafhankelijke positie als clinicus belangrijk te vinden. De opvatting van de docenten dat het door hen voorgeschotelde rolmodel erg belangrijk was, werd door de stagiaires niet gedeeld; zij zetten dat helemaal onderaan de lijst van belangrijke eigenschappen. ${ }^{4}$ Hieruit is op te maken dat er verschil in opvatting is tussen stagiaires en begeleiders over wat een goede invulling is van de rol van stagebegeleider: docent/voorbeeld (volgens de docenten) of begeleider van eigen activiteiten (volgens de stagiaires). Baars benoemt in een onderzoek naar de organisatie als leerplek nog een nieuw element van opleidersgedrag, namelijk het afwegen van aan de ene kant het belang van de individuele stagiaire, en aan de andere kant het belang van de organisatie. ${ }^{5}$

Binnen het Project Vernieuwing Huisartsopleiding (PVH) is een lijst van competenties samengesteld waarover de huisartsopleiders moeten beschikken. ${ }^{6}$ Die lijst is deels gebaseerd op het eerder genoemde rapport van de werkgroep 'Kwaliteit huisartsopleiders', maar draagt duidelijker dan dit rapport de signatuur van onderwijskundige vernieuwingen. Zo wordt er niet meer gesproken van kennis, vaardigheid en attitude maar van competenties. Deze competenties van de hao als opleider worden door aios aan het eind van hun stage in de huisartspraktijk beoordeeld, zowel in het eerste als in het laatste opleidingsjaar. Ze vullen daartoe een beoordelingslijst in. De lijst is samengesteld in samenwerking met de eerder genoemde werkgroep 'Kwaliteit huisartsopleiders'. ${ }^{7}$ Op de diverse instituten worden die beoordelingen per opleider opgeslagen om te gebruiken bij tussentijdse evaluaties van het functioneren van de huisarts als opleider.

Voorschrijven hoe het moet is één ding, maar dat geeft nog niet de garantie dat de huisartsen in de praktijk zich als opleiders ook zo gedragen. Via een dagboekmethode is dan ook onderzoek gedaan naar leergesprekken tussen aios en hao. ${ }^{8}$ Daarbij was het focus gericht op het soort leergesprek dat er gevoerd werd, de frequentie van de leergesprekken en op de door de aios beoordeelde kwaliteit ervan. De kwaliteit werd bepaald door vier kenmerken: het al of niet krijgen van feedback, het aantal gebruikte bronnen of materialen (literatuur, demonstratiemateriaal, video's, etc.), het aantal vervolgactiviteiten 
en - als negatief punt - het aantal onderbrekingen tijdens het leergesprek. Het meest voorkomende leergesprek was de nabespreking van consulten door de aios, gevolgd door dagrapportages. Deze dagboekmethode is een goede methode om het gedrag te registreren, maar stelt hoge eisen aan degene die het moet invullen. In dit onderzoek was de respons dan ook aan de lage kant wat de onderzoekers overigens weten aan enquêtemoeheid onder de toenmalige aios.

In een tevredenheidsonderzoek onder aios zijn vragen gesteld over de opleidingsactiviteiten van de opleider. ${ }^{9}$ Daaruit blijkt eveneens dat huisartsen nogal verschillen in de mate waarin zij (verplichte) opleidingsactiviteiten, zoals het houden van leergesprekken, het bekijken en bespreken van videobanden, verrichten.

Over de samenhang tussen gedrag van stagebegeleiders (zoals huisartsopleiders) en de mate waarin een stagiaire het vak leert werd één studie gevonden. In deze Britse studie van begeleidergedrag van tutoren bij studenten architectuur tijdens hun afstudeerproject, rapporteerden de studenten drie soorten docentengedrag: 1) gericht op goede relatie met student, 2) gericht op overbrengen van kennis en 3) de kritische volger van de student. De laatste benadering werd als het meest leerzaam ervaren. ${ }^{10}$

Uit de hierboven beschreven ontwikkelingen blijkt dat binnen de huisartsopleiding de competenties van de huisarts als opleider/stagebegeleider belangrijk worden gevonden. Diverse docentengedragingen worden daarbij onderscheiden. Deze komen enerzijds voort uit de tegenstelling tussen het klassieke docentgedrag (waarbij het overbrengen van kennis, vaardigheden en attitudes voorop staat) en het nieuwe leren (waarin kennisverwerving door de student via ervaring en reflectie op ervaring voorop staat). Anderzijds vindt men een tegenstelling tussen wat docenten en stagiaires belangrijk vinden: voorbeeld/docent zijn voor de stagiaire versus het kritisch volgen of begeleiden van de door de stagiaire ondernomen activiteiten. De discussie over wat effectief opleidersgedrag is speelt ook door in de didactische scholing van de huisartsopleiders. Doel van deze studie is meer inzicht te krijgen in de samenhang tussen het gedrag van de huisartsopleider als docent en de mate waarin de stage als leerzaam wordt ervaren. De vraagstellingen in deze studie zijn:

- Welke gedragingen vertonen huisartsen als opleiders en zijn daarin clusters (patronen) te ontdekken?

- Is er een samenhang tussen het door de huisartsopleiders vertoonde gedrag en de door de aios ervaren leerzaamheid van de stage?

\section{Methode}

\section{Context en proefpersonen}

Het onderzoek vond plaats binnen de Huisartsopleiding VUmc (HOVUmc). Aan het einde van elk stagejaar in de huisartspraktijk wordt op de HOVUmc een blokevaluatie afgenomen. Dit gebeurt aan de hand van een vragenlijst waarin aan de aios hun mening wordt gevraagd over de kwaliteit van en tevredenheid over dit blok. Voor dit onderzoek werd in 2003 deze vragenlijst uitgebreid met vragen over opleidersgedrag en leerervaringen. Deze vragenlijst werd afgenomen bij 166 aios die het eerste opleidingsjaar afsloten in respectievelijk maart 2003, 2004 en 2005.

\section{Instrument}

Er is een vragenlijst ontwikkeld om het opleidersgedrag van de hao vast te stellen. Op basis van de literatuur is uitgegaan van vijf gedragspatronen van de hao: 1 ) 
als voorbeeld, ${ }^{4}$ 2) als overbrenger van kennis, vaardigheden en attitudes, ${ }^{6} 3$ ) als begeleider van onderwijsactiviteiten van de aios, ${ }^{6}$ ) als persoon die een goede relatie met de aios wil onderhouden, ${ }^{10}$ en 5) als bewaker van de praktijkorganisatie. ${ }^{5}$ In overleg met docenten, aios en hao's zijn deze vijf aspecten van gedrag geoperationaliseerd in 17 waarneembare gedragingen, waarvan de aios kon aangeven hoe frequent ze voorkwamen tijdens de stage. De frequentie van gedragingen werd vastgelegd op een vijfpuntsschaal: 1 = kwam nooit voor, 2 = kwam zelden voor, 3 = kwam soms wel, soms niet voor, $4=$ kwam vaak voor en $5=$ kwam heel vaak voor. Voor deze schaalindeling naar gedragsfrequentie is gekozen omdat we meenden dat deze voor de aios het meest eenvoudig zou zijn. Een meer objectieve maat, met vragen naar frequentie in bijvoorbeeld aantal malen per week, per 14 dagen, per maand over een periode van een jaar, zou een te groot beroep doen op de herinnering van de aios.

Voor het meten van de ervaren effectiviteit van de stage werden drie aspecten onderscheiden. Ten eerste het globale leereffect: de bijdrage van de stage aan de vorming van de aios tot huisarts. Ten tweede de mate waarin de aios zich bewust is geworden van zijn/haar lacunes: wat hij/zij (nog) niet beheerst aan onderdelen van competenties. En tot slot de mate waarin de aios zich bewust is geworden van zijn/haar sterke punten: waar hij/zij meer dan gemiddelde kwaliteiten heeft. Lacunes en sterke punten worden als leereffecten apart benoemd omdat Korthagen en Vasalos stellen dat het bewust maken van sterke punten het leren sterker stimuleert dan het ingaan op tekortkomingen. ${ }^{12}$ Het globaal ervaren leereffect werd aangegeven op een schaal lopend van 1 = zeer gering tot $5=$ zeer groot.
De twee overige leereffecten werden geformuleerd in stellingen waarop de aios op een vijfpuntsschaal kon aangeven in hoeverre hij of zij het eens was met de betreffende stelling (hierbij was 1 = geheel mee oneens en 5 = geheel mee eens).

\section{Analyse}

De gedragingen van de huisartsopleiders werden vastgesteld door per gedragsitem zowel de percentages van de scores als het schaalgemiddelde te berekenen. De samenhang in het voorkomen van gedragingen werd via factoranalyse vastgesteld (met behulp van het programma SPSS, versie 11.1). De door de respondenten gescoorde gedragingen (zie tabel 1) zijn op basis van hun onderlinge samenhang ondergebracht in verschillende 'factoren'. Voor elk gedragsaspect is een relatie berekend met die factor (de factorlading). Hiermee herbergt de factor een reeks van statistisch met elkaar samenhangende gedragingen. Gekozen is voor een Principal Components Analysis. Ten behoeve van de interpreteerbaarheid van de oplossing werd een varimax rotatie toegepast. Alleen factoren met een eigenvalue boven 1,00 werden meegenomen in de oplossing. Gedragsitems met een lading lager dan 0.30 werden niet betrokken bij de bepaling van de betekenis van de factor. De benoeming van de factoren werd gedaan door aan een aan de opleiding voor de huisartsopleiders verbonden staflid, aan een staflid/onderwijscoördinator die zich heeft bezig gehouden met de rol van de huisarts als opleider en aan een huisartsopleider-onderzoeker, de factoren met hun ladingen voor te leggen en aan hen te vragen consensus te verkrijgen over de benoeming van die factoren. Voor de beantwoording van de vraag of er een samenhang bestaat tussen het door de huisartsopleider vertoonde gedrag en het ervaren leereffect van de stage, werden 
voor elke gedragsfactor die uit de bovengenoemde factoranalyse kwam, factorscores vastgelegd. Pearson productmoment correlatiecoëfficiënten werden berekend tussen deze factorscores en de drie niveaus van de leerzaamheid van de stage.

\section{Resultaten}

Van de 166 verstuurde formulieren werden 117 ingevuld geretourneerd: een respons van $70 \%$.

\section{Gedrag van huisartsopleiders}

De frequenties van de gedragingen die van huisartsen als opleider verwacht worden lieten grote verschillen zien (tabel 1). Gedragingen die relatief vaak voorkomen zijn: eigen planning laten maken (78\% vaak - zeer vaak), eigen leerdoelen laten formuleren (70\%), aandacht geven aan het goed afhandelen van patiënten $(67 \%)$, eigen prestaties laten beoordelen $(59 \%)$ en uitleggen hoe iets gedaan moet worden (59\%). Gedragingen die relatief weinig werden

Tabel 1. Frequentie waarmee huisartsen in opleiding gedragingen waarnamen van hun opleiders.

\begin{tabular}{|c|c|c|c|c|c|c|c|}
\hline \multirow[t]{2}{*}{ Gedrag: de huisartsopleider } & \multirow[t]{2}{*}{ Aantal } & \multicolumn{6}{|c|}{ Deed uw opleider (in percentages van aantal (kolom 2): } \\
\hline & & $\begin{array}{c}\text { nooit } \\
\text { score } 1\end{array}$ & $\begin{array}{l}\text { weinig } \\
\text { score } 2\end{array}$ & $\begin{array}{c}\text { soms wel, } \\
\text { soms niet } \\
\text { score } 3\end{array}$ & $\begin{array}{c}\text { vaak } \\
\text { score } 4\end{array}$ & $\begin{array}{c}\text { zeer vaak } \\
\text { score } 5\end{array}$ & $\begin{array}{c}\text { gemiddel- } \\
\text { de score }\end{array}$ \\
\hline Demonstreerde hoe $u$ iets moest aanpakken & 115 & 6.0 & 13.8 & 31.9 & 35.3 & 12.9 & 3.35 \\
\hline Legde uit hoe $u$ iets moest doen & 116 & 1.7 & 9.5 & 29.3 & 46.6 & 12.9 & 3.59 \\
\hline Gaf aan wat $u$ in zijn/haar ogen niet goed deed & 117 & 6.0 & 12.0 & 29.1 & 42.7 & 10.3 & 3.39 \\
\hline $\begin{array}{l}\text { Gaf aan wat } u \text { moest doen om iets } \\
\text { (kennis of vaardigheden) te leren }\end{array}$ & 116 & 8.6 & 19.8 & 38.8 & 25.0 & 7.8 & 3.03 \\
\hline $\begin{array}{l}\text { Maakte afspraken over wanneer } u \\
\text { iets bestudeerd moest hebben }\end{array}$ & 114 & 33.3 & 23.7 & 24.6 & 12.3 & 6.1 & 2.34 \\
\hline $\begin{array}{l}\text { Liet } u \text { voordoen hoe of vertellen hoe } \\
u \text { iets (bv. een vaardigheid) aanpakte }\end{array}$ & 114 & 7.9 & 19.3 & 27.2 & 36.8 & 8.8 & 3.19 \\
\hline Liet u uw eigen leerdoelen formuleren & 117 & 1.7 & 7.7 & 20.5 & 40.2 & 29.9 & 3.89 \\
\hline Liet u uw eigen prestaties beoordelen & 117 & 0.9 & 16.2 & 23.1 & 41.0 & 18.8 & 3.61 \\
\hline Liet $u$ uw eigen planning maken & 116 & 0.9 & 4.3 & 16.4 & 42.2 & 36.2 & 4.09 \\
\hline Besprak met u uw planning & 113 & 4.4 & 15.0 & 35.4 & 26.5 & 18.6 & 3.40 \\
\hline $\begin{array}{l}\text { Gaf aandacht aan uw omstandigheden } \\
\text { voor zover die uw leren bemoeilijkten }\end{array}$ & 110 & 8.2 & 8.2 & 29.1 & 39.1 & 15.5 & 3.45 \\
\hline Gaf aandacht aan uw motivatie voor het vak & 116 & 4.3 & 19.0 & 25.9 & 36.2 & 14.7 & 3.38 \\
\hline Gaf aandacht aan uw motivatie om te leren & 115 & 3.5 & 17.4 & 33.9 & 32.2 & 13.0 & 3.34 \\
\hline $\begin{array}{l}\text { Gaf aandacht aan de relatie tussen } \\
\text { hem/haar en } u\end{array}$ & 115 & 7.8 & 14.8 & 30.4 & 33.0 & 13.9 & 3.30 \\
\hline $\begin{array}{l}\text { Gaf aandacht aan het goed afhandelen van } \\
\text { patiënten die } u \text { gezien had of moest zien }\end{array}$ & 114 & 1.8 & 6.1 & 25.4 & 51.8 & 14.9 & 3.72 \\
\hline Gaf aandacht aan collegiale samenwerking & 116 & 2.6 & 14.7 & 41.4 & 32.8 & 8.6 & 3.30 \\
\hline $\begin{array}{l}\text { Gaf aandacht aan normen en } \\
\text { regels in de praktijk van uw opleider }\end{array}$ & 116 & 6.0 & 14.7 & 42.2 & 28.4 & 8.6 & 3.19 \\
\hline
\end{tabular}


gemeld door de aios zijn: aangeven wat gedaan moet worden om iets (kennis of vaardigheden) te leren (33\%) en afspraken maken over de termijn waarop iets bestudeerd moet zijn (18\%).

De factoranalyse die uitgevoerd werd om samenhang in gedragingen te vinden leverde vier factoren op, die samen $65 \%$ van de totale variantie in de scores op de 17 gedragingen verklaarden (tabel 2). Het voorleggen van deze factoren aan de genoemde deskundigen leverde de volgende benoeming op:
- Factor 1: feedback gevend docentgedrag; hierbij is overeenstemming verkregen over de opvatting dat het gedragsitem dat oorspronkelijk afgeleid was van het gedrag 'als voorbeeld dienen' (namelijk 'demonstreerde hoe U (= de aios) iets moest aanpakken') ook als docentgedrag kon worden beschouwd.

- Factor 2: affectief coachingsgedrag.

- Factor 3: zelfstudie stimulerend begeleidingsgedrag.

- Factor 4: op samenwerking in de huisartspraktijk gericht gedrag.

Tabel 2. Resultaat van de factoranalyse over 17 gedragingen van huisartsen als opleiders. ${ }^{*}$

\begin{tabular}{|c|c|c|c|c|}
\hline Gedragingen van: de huisartsopleider & $\begin{array}{c}\text { Factor } 1 \text {, } \\
\text { eigenvalue } \\
6.5\end{array}$ & $\begin{array}{c}\text { Factor } 2 \text {, } \\
\text { eigenvalue } \\
2.0\end{array}$ & $\begin{array}{c}\text { Factor } 3, \\
\text { eigenvalue } \\
1.5\end{array}$ & $\begin{array}{c}\text { Factor 4, } \\
\text { eigenvalue } \\
1.04\end{array}$ \\
\hline Demonstreerde hoe $u$ iets moest aanpakken & 0.73 & & & \\
\hline Legde uit hoe $\mathrm{u}$ iets moest doen & 0.76 & & & \\
\hline $\begin{array}{l}\text { Gaf aan wat } u \text { in zijn/haar ogen niet goed of } \\
\text { wel goed deed }\end{array}$ & 0.78 & & & \\
\hline Gaf aan wat $u$ moest doen om iets te leren & 0.72 & & & \\
\hline $\begin{array}{l}\text { Maakte afspraken over wanneer } \mathrm{u} \text { iets bestudeerd } \\
\text { moest hebben }\end{array}$ & 0.57 & & & -0.40 \\
\hline $\begin{array}{l}\text { Liet } u \text { voordoen of vertellen hoe } u \text { iets } \\
\text { (bijv. een vaardigheid) aanpakte }\end{array}$ & 0.71 & & & \\
\hline Liet $u$ uw eigen leerdoelen formuleren & & & 0.84 & \\
\hline Liet $u$ uw eigen prestaties beoordelen & & & 0.73 & \\
\hline Liet $u$ uw eigen planning maken & & & 0.69 & 0.50 \\
\hline Besprak met u uw planning & 0.41 & & 0.50 & \\
\hline $\begin{array}{l}\text { Gaf aandacht aan uw omstandigheden voor } \\
\text { zover die uw leren bemoeilijkten }\end{array}$ & & 0.43 & & 0.58 \\
\hline Gaf aandacht aan uw motivatie voor het vak & & 0.87 & & \\
\hline Gaf aandacht aan uw motivatie om te leren & & 0.85 & & \\
\hline $\begin{array}{l}\text { Gaf aandacht aan de relatie tussen hem/haarzelf } \\
\text { en } u\end{array}$ & & 0.73 & 0.35 & \\
\hline $\begin{array}{l}\text { Gaf aandacht aan het goed afbehandelen van } \\
\text { patiënten die u gezien had of nog moest zien }\end{array}$ & 0.63 & & & 0.39 \\
\hline Gaf aandacht aan collegiale samenwerking & & 0.34 & & 0.74 \\
\hline $\begin{array}{l}\text { Gaf aandacht aan de normen en regels in de } \\
\text { praktijk van uw opleider }\end{array}$ & & 0.46 & & 0.50 \\
\hline
\end{tabular}

* Model: principal components, met varimax rotatie. 


\section{Ervaren leerzaamheid stage en samen- hang met gedrag opleider}

In tabel 3 worden de frequenties van de scores op de ervaren leerzaamheid en hun gemiddelden weergegeven. In het algemeen vinden de aios de bijdrage van de stage aan hun vorming tot huisarts groot tot zeer groot (91\%). Ze worden zich ook sterk tot zeer sterk bewust van hun lacunes $(91 \%)$ en hun kwaliteiten (89\%). Drie factoren, namelijk feedback gevend docentgedrag, affectief coachingsgedrag en zelfstudie stimulerend begeleidingsgedrag, vertonen samenhang met de bijdrage die de stage heeft geleverd aan de vorming tot huisarts (tabel 4). Bewustwording van lacunes hangt samen met feedback gevend docentgedrag, zelfstudie stimulerend begeleidingsgedrag en met gedrag dat gericht is op samenwerking in de praktijk. Bewustwording van eigen kwaliteiten hangt samen met zelfstudie stimulerend begeleidingsgedrag en met gedrag dat gericht is op samenwerking in de praktijk. Factor 3 (zelfstudie stimulerend begeleidingsgedrag) vertoont samen- hang met scores op alle drie genoemde leerzaamheidsvragen, en laat ook de hoogste correlatiecoëfficiënt zien.

\section{Discussie}

Uit deze studie komt naar voren dat huisartsopleiders vaak de stagiaires hun eigen leerplanning laten maken en hun leerdoelen laten formuleren. Daarnaast gaan ze met hun stagiaires na of de patiënten die door die stagiaires zijn gezien wel goed behandeld zijn, doen ze de vaardigheden voor en laten ze de stagiaire zichzelf beoordelen. Wat huisartsopleiders weinig deden was het maken van afspraken met hun stagiaires over de termijn waarop iets bestudeerd moet zijn en het met hen bespreken hoe ze iets moeten leren. Kortom: verantwoordelijkheid, aanpak en beoordeling van het leerproces leggen huisartsopleiders in het algemeen bij hun aios, maar ze gaan wel na of hun patiënten goed behandeld worden.

We vonden vier clusters van gedragingen: het geven van feedback, het affectief coachen, het stimuleren van zelfstudie en

Tabel 3. Scores op vragen naar bijdrage van de stage aan het leerproces van de aios.*

\begin{tabular}{|c|c|c|c|c|c|c|c|}
\hline Stellingen & aantal & $\begin{array}{c}\text { score } 1 \\
\text { (in } \% \text { ) }\end{array}$ & $\begin{array}{c}\text { score } 2 \\
\text { (in \%) }\end{array}$ & $\begin{array}{c}\text { score } 3 \\
\text { (in \%) }\end{array}$ & $\begin{array}{c}\text { score } 4 \\
\text { (in } \% \text { ) }\end{array}$ & $\begin{array}{c}\text { score } 5 \\
\text { (in } \% \text { ) }\end{array}$ & $\begin{array}{l}\text { gemiddelde } \\
\text { score }\end{array}$ \\
\hline $\begin{array}{l}\text { 1: De bijdrage van de stage in } \\
\text { de huisartspraktijk tot mijn } \\
\text { vorming als huisarts }\end{array}$ & 114 & & 2.6 & 6.1 & 27.2 & 64.0 & 4.53 \\
\hline $\begin{array}{l}\text { 2: Door mijn stage in de } \\
\text { huisartspraktijk ben ik me } \\
\text { meer bewust geworden van } \\
\text { mijn lacunes }\end{array}$ & 114 & & 1.8 & 5.3 & 54.4 & 38.6 & 4.30 \\
\hline $\begin{array}{l}\text { 3: Door mijn stage in de } \\
\text { huisartspraktijk ben ik me } \\
\text { meer bewust geworden van } \\
\text { mijn kwaliteiten }\end{array}$ & 114 & 0.9 & 0.9 & 9.6 & 44.7 & 43.9 & 4.30 \\
\hline
\end{tabular}


Tabel 4. Samenhang tussen de factorscores van de vier factoren* en de scores op de vragen naar de bijdrage van de stage in de huisartspraktijk.**

\begin{tabular}{|c|c|c|c|c|}
\hline & factor 1 & factor 2 & factor 3 & factor 4 \\
\hline \multicolumn{5}{|l|}{ Bijdrage van stage aan mijn } \\
\hline vorming tot huisarts & $0.22 .(p=0.028)$ & 0.23. $(p=0.021)$ & $0.44 .(p=0.000)$ & \\
\hline Bewustwording van lacunes & $0.21(p=0.04)$ & & $0.27 .(p=0.008)$ & $0.26 .(p=0.010)$ \\
\hline Bewustwording van kwaliteiten & & & $0.25 .(p=0.015)$ & $0.31(p=0.002)$ \\
\hline
\end{tabular}

het stimuleren van de samenwerking in de praktijk. Elk van die vier clusters vertoonde een aparte samenhang met de drie leereffecten waarop de stage werd gewaardeerd.

Het leereffect 'door de aios ervaren bijdrage van de stage aan diens vorming tot huisarts' correleerde sterk met het opleidersgedrag 'zelfstudie stimuleren', en zwak met 'feedback geven' en 'affectief coachen'. Het tweede leereffect 'bewustwording van eigen lacunes' correleerde sterk met 'stimuleren van samenwerking in de praktijk' en zwak met 'feedback geven' en 'zelfstudie stimuleren'. Het derde leereffect 'bewustwording van eigen kwaliteiten' correleerde sterk met 'stimuleren van samenwerking in de praktijk' en zwak met 'zelfstudie stimuleren'.

De resultaten van deze studie liggen in de lijn van de bevindingen van Buchel et al. namelijk dat artsen in opleiding willen dat stagebegeleiders hun autonomie en onafhankelijkheid als arts respecteren, terwijl de stagebegeleiders hun functie als rolmodel het belangrijkst achten. ${ }^{4}$

Dit onderzoek heeft een aantal beperkingen. Eerder is aangegeven dat ervaren leerzaamheid en objectief gemeten leereffecten nauwelijks samenhangen. ${ }^{11}$ Kortom: hoewel deze gerapporteerde onder- zoeksgegevens iets zeggen over het verband tussen opleidersgedrag en het door de aios ervaren leereffect van de stage, mag men niets aannemen over het verband tussen opleidersgedrag en objectief gemeten leereffecten van de stages. Daarvoor moet apart onderzoek worden gedaan. Verder kan opgemerkt worden dat de in de methodenparagraaf genoemde vijf gedragspatronen niet allemaal even sterk zijn uitgewerkt in de vragenlijst. Zo is er slechts één gedragsitem (namelijk 'demonstreerde hoe u iets moest aanpakken') afgeleid van het patroon 'voorbeeld zijn'. Dit kan er mede de oorzaak van zijn dat er uit de factoranalyse geen vijf maar vier factoren kwamen. Dat het gedragspatroon 'voorbeeld zijn' niet als aparte factor uit de analyse kwam, kan ook komen omdat het van het functioneren als voorbeeld afgeleide gedrag 'demonstreerde hoe u iets moest aanpakken' een hoge lading heeft op de factor 'feedback geven'. Dat wijst ook op de mogelijkheid dat huisartsopleiders die iets voordoen, ook graag feedback geven zodat 'voorbeeld zijn' en 'feedback geven' gedragingen zijn die veel samengaan.

De boodschap uit het onderzoek is: laat de huisartsen in opleiding vooral veel hun eigen gang gaan en stimuleer ze in de 
planning van hun leeractiviteiten. Dit zal ertoe leiden dat zij hun huisartsenstage als het meest leerzaam ervaren en hen leren hun eigen kwaliteiten en lacunes te (onder)kennen. Uit de resultaten van deze studie blijkt dat de opleiders de aios wel vrij laten in het plannen van hun leeractiviteiten maar niet in het behandelen van de patiënten. In de didactische scholing van huisartsopleiders zou men nog meer dan misschien nu het geval is de nadruk kunnen leggen op het begeleiden van leeractiviteiten. Dan zou de door de aios ervaren bijdrage van de stage bij de huisarts aan hun vorming tot huisarts nog beter worden gediend.

\section{Literatuur}

1. Willems W, Duin B van. Opleidingsplan Huisartsopleiding VUmc. Amsterdam: maart 2006, p 8-9. [Programme for vocational general practice training, VU Medical Center. Amsterdam: march 2006, p 8-9].

2. SVUH-werkgroep Kwaliteit Huisartsopleiders: kwaliteitsnormen voor de huisartsopleider. Utrecht: SVUH; januari 2004. [Study group National Centre for Evaluation of Postgraduate Training in General Practice: Quality criteria for general practice trainers. Utrecht: SVUH; january 2004].

3. Boendermaker PM: Meestersschap. Van verkenning naar herkenning van de goede huisartsopleider. Maarsen: Elsevier gezondheidszorg; 2003. [Mastery. From exploration to recognition of the competent general practice trainer. Maarssen: Elsevier Health Care: 2003].

4. Buchel TL, Edwards FD. Characteristics of effective clinical teachers. Fam Med 2005;37(1):30-5.

5. Baars-van Moorsel M. Leerklimaat: de culturele dimensie van leren in organisaties. Delft: Eburon; 2003. [The learning environment: the cultural dimensions of learning in organisations. Delft: Eburon;2003].

6. Project Vernieuwing huisartsopleiding: Competenties van huisartsopleiders; Utrecht; maart 2006. [Project Changes in vocational general practice training: The competencies of general practice trainers. Utrecht; march 2006].

7. Kronjee D, Ram P. Schriftelijke toetsing van de HAO door de HAIO. UMC Maastricht; november 2004. [Written assessment of general practice trainers by general practice trainees. University Medical Centre Maastricht; november 2004].
8. Tan LHC, Kramer AWM. Opleiding doorgelicht. Evaluatie driejarige huisartsopleiding. Eindrapportage EVA-H project. Utrecht: SVUH; oktober 1999, p 45-51. [An investigation of training. Evaluation of the three-year vocational general practice training programme. Final report of the EVA-H project. Utrecht: National Centre for Evaluation of Postgraduate Training in General Practice; october 1999, p 45-51].

9. Suhre C. Tussen wens en werkelijkheid. Verslag van een opinieonderzoek naar de kwaliteit van de Groningse huisartsopleiding. Groningen: COWOG; 2003. [Between wish and reality. Report of a survey on the quality of the Groningen vocational general practice training programma. Groningen: Groningen University Education Centre; 2003].

10. Webster H. Facilitating critically reflective learning; excavating the role of the design tutor in architectural education; paper presented at the Shared Vision Conference 1-3 September 2002, Brighton, UK incorporating Architectural Education Exchange 2002.

11. Kramer AWM, Zuithoff P, Jansen JJM ,Tan LHC, Grol RPTM , Vleuten CPM van der. Groei van zelf ervaren klinische competentie in de huisartsopleiding en factoren die daarop van invloed zijn. Tijdschrift voor Medisch Onderwijs 2006; 25(3): 134-42. [Growth of self-perceived clinical competence in postgraduate training for general practice and its relation to potentially influencing factor. Dutch Journal of Medical Education 2006; 25(3):134-42].

12. Korthagen F, Vasalos A. Kwaliteit van binnenuit als sleutel voor professionele ontwikkeling. Tijdschrift voor lerarenopleiders 2007;28(1):17-23. [Inner quality as the key to professional development. Journal of Teacher Education 2007;28(1): 17-23].

De auteurs:

Dr. G. Locher is gedragswetenschappelijk docent en kwaliteitsmedewerker aan de huisartsopleiding van het VUmc.

Dr. A.H. Blankenstein is huisarts en wetenschappelijk onderzoeker aan het EMGO instituut van het VUmc.

\section{Correspondentieadres:}

G. Locher en A.H. Blankenstein, Huisartsopleiding VUmc, OZW, De Boelelaan 1109,1081 HV Amsterdam; email: g.locher@vumc.nl

Belangenconflict: geen gemeld.

Financiële ondersteuning: geen gemeld. 


\section{Summary}

Introduction: Recent changes in vocational general practice training in the Netherlands have raised the questions whether the same teaching behaviours of general practice trainers that were appropriate for the old programme are suitable for the new one and what is the contribution of different teaching behaviours to the quality of training. We conducted a study into the frequency and effectiveness of teaching and supervision by general practice trainers as perceived by trainees.

Method: All 166 trainees in the Department of General Practice, VU Medical Center, who completed their first year of vocational general practice training in 2003-2005 received a questionnaire asking them to indicate the frequency of 17 teaching behaviours on a five-point scale. Factor analysis was performed to identify behaviour patterns and factor scores were calculated for each factor. The trainees were also asked to rate on a five-point scale: 1) the overall effectiveness of training; the contribution of training to their awareness of 2) gaps in their competencies and 3) of their strengths.

Results: 117 trainees (70\%) completed the questionnaire. Four behaviour clusters explained 65\% of the total variance: 1) giving feedback, 2) affective aspects of coaching, 3) stimulating independent learning and 4) promoting teamwork in practice. The strongest correlation was found between the third factor and overall effectiveness of training.

Discussion: The effectiveness of general practice training is related to trainer behaviour aimed at stimulating the learning of trainees. Training programmes for trainers should focus on these behaviours rather than on specific teaching activities. (Locher G, Blankenstein AH. Teaching behaviours of GP trainers. Relationship between the behaviours of GP trainers and the effectiveness of training as experienced by GP trainees. Dutch Journal of Medical Education 2008;27(2):70-79.) 